\title{
Immunogenicity Specimen Assessments Method
}

National Cancer Institute

\section{Source}

National Cancer Institute. Immunogenicity Specimen Assessments Method. NCI

Thesaurus. Code C117568.

The technique used to administer the immunogenicity specimen assessment. 